\title{
Sustainable development induction in organizations: a convergence analysis of ISO standards management tools' parameters
}

\author{
Fabrício Kurman Merlin ${ }^{\mathrm{a},{ }^{*}}$, Vera Lúcia Duarte do Valle Pereira a and Waldemar Pacheco Júnior ${ }^{\mathrm{a}}$ \\ a Production Engineering and Systems Department, Santa Catarina Federal University, Campus Universitário - \\ Trindade - PO Box 476, Florianópolis-SC, Brazil
}

\begin{abstract}
Organizations are part of an environment in which they are pressured to meet society's demands and acting in a sustainable way. In an attempt to meet such demands, organizations make use of various management tools, among which, ISO standards are used. Although there are evidences of contributions provided by these standards, it is questionable whether its parameters converge for a possible induction for sustainable development in organizations. This work presents a theoretical study, designed on structuralism world view, descriptive and deductive method, which aims to analyze the convergence of management tools' parameters in ISO standards. In order to support the analysis, a generic framework for possible convergence was developed, based on systems approach, linking five ISO standards (ISO 9001, ISO 14001, OHSAS 18001, ISO 31000 and ISO 26000) with sustainable development and positioning them according to organization levels (strategic, tactical and operational). The structure was designed based on Brundtland report concept. The analysis was performed exploring the generic framework for possible convergence based on Nadler and Tushman model. The results found the standards can contribute to a possible sustainable development induction in organizations, as long as they meet certain minimum conditions related to its strategic alignment.
\end{abstract}

Keywords: Sustainable Development, Management, Systems, ISO Standards, Organizations, Strategic Alignment

\section{Introduction}

Dealing on sustainable development covers a set of issues involving different society segments demands [1]. Organizations take part of an environment in which they are increasingly being pressed to meet such demands (economic, environmental and social) and consequently, in a way it shall be carried out sustainably $[1,2]$. In an attempt to meet them, organizations make use of various management tools, among which, one of the most used are the ISO's standards.

Although there is evidence of contributions provided by these standards in the literature, due to its characteristics and implications of its use in the organization's elements, it is questionable whether its parameters converge for a possible sustainable development induction in organizations.
This work presents a theoretical study, designed on the structuralism world view, descriptive and deductive method, which aims to analyze the ISO standards management tools' parameters convergence for possible sustainable development induction in the organization. In order to support the analysis, a generic framework for possible convergence was developed, based on systems approach, linking five ISO standards (ISO 9001, ISO 14001, OHSAS 18001, ISO 31000 and ISO 26000) with sustainable development and positioning them according to organization levels (institutional, tactical and operational). The structure was designed based on the Brundtland report sustainable development concept. The analysis was performed exploring the generic framework for possible convergence in the lens of Nadler and Tushman model. The paper is organized in five sections. Section 1, presents the introduction; Section 2 presents the

Corresponding author. Email: merlin.fabricio@gmail.com 
background which allowed the generic structure for possible induction construction and analysis; Section 3 presents the methodological proceedings; Section 4 presents the generic structure construction and ISO's management tools parameters analysis results; and Section 5 presents the final conclusions.

\section{Background}

\subsection{Sustainable Development Concept}

Pezzey [2] reported twenty-seven concepts of sustainable development based on the literature, although not exhausted. From the definitions presented by Pezzey, sustainable development concept popularization is generally credited to Brundtland Report [2], prepared by the United Nations World Commission on Environment and Development (UNWCED). According to UNWCED sustainable development is the development that meets the needs of present generations without compromising the ability to meet the needs of future generations. From this definition, the approach of UNWCED [3] emphasized the need for new concepts for global development that: (1) recognize the fact that social and environmental problems are interrelated, (2) recognition that environmental stress does not only restrict to particular sites or geographical boundaries, (3) recognition that environmental disasters witnessed in a region of the planet, ultimately, affect the welfare of everyone, everywhere, and, (4) the recognition that only through a sustainable approach to development could protect the fragile ecosystems of the Earth and allow human development and perpetuity.

\subsection{Systems Approach}

Systems approach (or systemic thinking) can be considered as a new way of thinking in terms of connectedness, relationships and context $[4,5]$. It began with organismic scientists during the first half of the twentieth century, among which can be highlighted the Russian Alexander Bogdanov and the Austrian Ludwig von Bertalanffy (who proposed an interdisciplinary theory, called General Systems Theory) [5].

Basically, the systems approach sought to provide a change of focus on three dominant intellectual principles: reductionism, analytical thinking and mechanicism for the expansionism, synthetic thought and teleology, respectively [4]. Table 1 presents ten features listed by Katz and Kahn, based on the results of Ludwig von Bertalanffy's work, to set all open systems (inclusive organizations).

$$
\text { Table } 1
$$

Katz and Kahn's ten features in defining open systems. Source: Adapted from Jackson [6].

Description of Features

1. The import of energy from the external environment.

2. Input rate and transformation into the system.

3. The output exported to the environment

4. Systems as event cycle: outputs give rise to new energy sources for the entries, then cycle begins again.

5. Negative entropy: open systems living outside their environment, getting more energy than they expend.

6. Information input, negative feedback and coding process: the system selectively collect information about its environment and own activities (so they can take corrective action).

7. Steady state and dynamic homeostasis, despite the continuous inflow and export of energy, the system's characteristics remains.

8. Differentiation: open systems move toward differentiation and development of structures (for example, greater specialization of functions).

9. Integration and coordination to ensure unified operation.

10. Equifinality: a system can achieve by more than one way, the same final state starting from different initial conditions.

\subsection{Nadlder and Tushman Model}

Nadler and Tushman model [7] provides a generic framework that assists in managing the organization. Aims at a better organizational performance, seeking congruence both with its parts and the environment in which it operates.

According to this model, organizations can be viewed as an open system, composed by four elements: task, individual, organizational arrangements (formal organization) and informal organization. Fig. 1 represents the complete model.

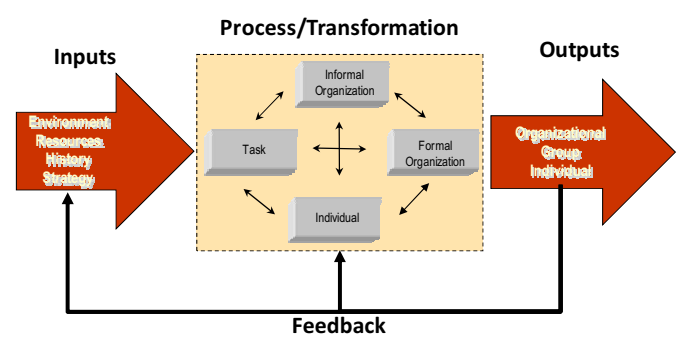

Fig. 1 - Nadler and Tushman model. Source: Adapted from Nadler and Tushuman [7] 
Combination among system's parts is performed based on the following entries: the external environment of the organization, which causes impacts on it; the necessary resources organization has access; organization's history, paying attention to the patterns of its behavior in the face of adversities; and strategies defined from the organization's objectives.

For each pair of entries in the system organization, there is a relative degree of congruence, consistency or combination of them. This consistency should be sought for the system components.

\subsection{ISO Standards}

The first two editions of the ISO 9000 series published in 1987 and revised in 1994 had a system whose focus was to allow organizations always produce the same quality through specification of policies, procedures and instructions in quality manual [8]. With the revision of ISO 9001 in 2000 (and given continuity in the 2008 version), the focus has become stronger on the clients orientation and the issue of continuous improvement.

ISO 26000 was published in September 2010. This standard provides guidance on: the principles of social responsibility; the recognition of social responsibility and participation of stakeholders in seven central themes and issues of social responsibility; and, ways to integrate socially responsible behavior for the organization. This standard adopts the Brundtland Report sustainable development concept. Social responsibility has its focus on the organization and therefore the responsibilities and concerns of this to society and the environment [9]. So, social responsibility is closely linked to sustainable development [9]. As sustainable development is about the economical, social and environmental common to all people, it can be used as a way to summarize the broader societies' expectations that need to be taken into consideration by organizations seeking to act in a responsible manner [9].

ISO 14001 was first published in 1996 and had a review published in November 2004 [8]. International standards for environmental management are intended to provide organizations with the elements of an effective environmental management system (EMS), which can be integrated with other management requirements and help organizations achieving their environmental and economic goals
ISO 31000:2009 (risk management - Principles and Guidelines) was published in November 2009. Although ISO standards in risk management area have been produced before, this is the first time that an ISO standard is claimed for managing all risks across the organization [10]. The need for developing such a standard is based on the premise that organizations of all types and sizes face internal and external factors that influence uncertainty for goal reaching [10].

The Occupational Health and Safety Assessment Series (OHSAS) is a standard developed by the British Standards Institute (BSI) in partnership with other international certification for the management system of occupational health and safety (OHSMS) [8]. Its first publication was in 1999, revised in 2007.

\section{Methodological proceedings}

This research is characterized by the structuralist world view, which considers the object of study lying in the relations among elements of a process in phenomena explanation $[11,12]$. The research method is characterized as deductive [11.13]. Related to its characteristics, it is classified as a theoretical research, qualitative nature and descriptive [11]. Data was collection through technique based on literature $[11,13]$.

Research elaboration consists by the following steps:

1. Sustainable development definition (section 2.1);

2. System approach considering organizations (sections 2.2 e 2.3 );

3. ISO Standards identification (section 2.4);

4. Generic structure for possible convergence elaboration (section 4.1); and,

5. Convergence analysis of ISO standards management tools' parameters for sustainable development possible induction in organization (section 4.2).

\section{Results}

\subsection{Generic structure for possible convergence}

There is a relationship of dependency and influence between organization and environment and the influence exerted by the environment on the organization is generally greater than the influence exerted by the organization on the environment. This 
suggests that organization must meet and adapt to environmental demands in order to continue existing.

The UNWCED [3] sustainable development concept, brought to the organizational context implies the pursuit of development that allows the organization meet the needs or demands, both of present and future generations. Meeting these demands, in turn, is carried out based on the available and usable resources, which are known at present.

The available resources and the implications must be considered simultaneously in three dimensions: environmental, economic and social [14]. These implications or effects resulting from actions taken by the present generation are called impacts. The available and usable resources, as already seen, can be represented, broadly, in terms of materials (m), energy $(\xi)$ and information (i) [15]. The use of these resources could impact in positive $(+)$, negative $(-)$ and/or neutral $(\varnothing)$, both present and future generations.

Thus, the sustainable development concept translated into a language understood by the system organization implies considering as one of its purposes (or goals), meeting the society's demands, seeking available and usable resources maintenance, associated with the identified demands.

Fig. 2 shows the environment, inputs, outputs, purpose of the system (it is recognized that the stated purpose is not the only, but one emphasized in this work), and the feedback process (although as a black box being investigated).

ENVIRONMENT

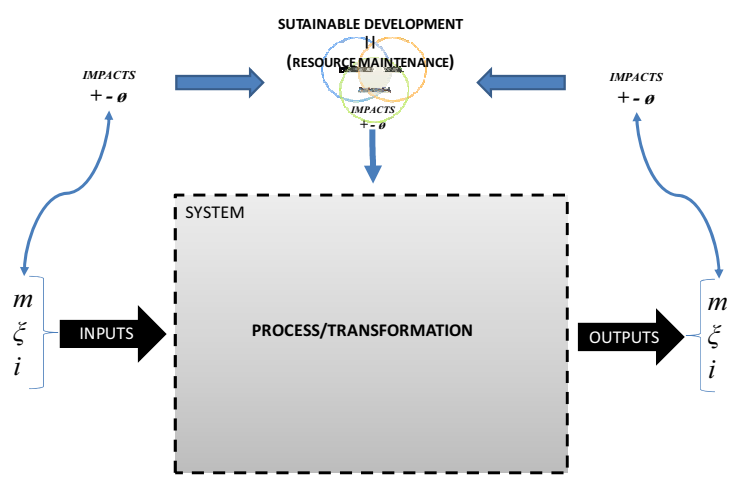

Fig. 2 - Partial generic structure representation showing interaction between system and external environment. Source: Merlin [16].

When organizations are studied under systems approach perspective, the parties did not refer specifically to the individuals involved in the organization, but the role (or roles) each one plays within these. Pacheco Jr. et al. [15] show that individuals involved in the organization play roles involving the development of conceptual, human and technical skills. These skills' combination and distribution along with the tasks generally allows the organization establishing three levels within it: strategic, tactical and operational level. They are responsible for the operation (and also by the behavior) of the system organization. Its operation, as well as their behavior will result from the interaction or the relationship among these organizational levels.

From the three organizational levels identification, it is possible to recognize and propose an ISO standards positioning in system organization (Fig. 3). This position allows seeing the emphasis given to the relationships among the standards and organizational levels. It is also possible to recognize and position the sustainable development concept and how it will influence the organizational levels and their relationships.

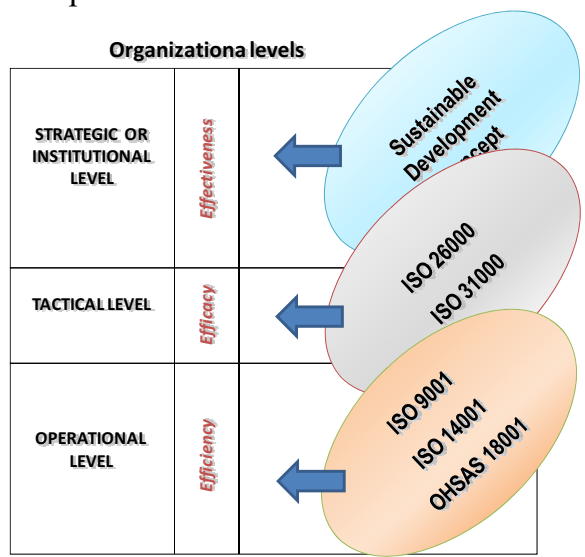

Fig. 3 - Sustainable development concept and ISO Standards positioning at the organizational levels. Source: Merlin [16].

According to Capra [5] systemic thinking consists of two wires: the contextual thinking and process thinking. Only by considering the two thoughts at the same time, one can see the emerging features from the relationship between system (from the interactions among its parts) and the environment. Fig. 4 shows the dynamics established through systemic thinking, the placement of standards relating to organizational levels.

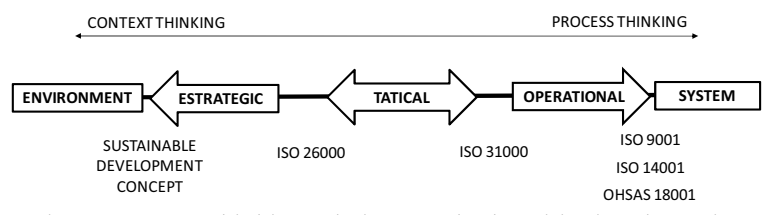

Fig. 4 - System thinking relating standard positioning dynamics related towards organizational levels. Source: Merlin [16]. 
In organizations, it is up to strategic level establishing organizational goals, as well as dealing with conceptual issues. Thus, the sustainable development apprehended by contextual thought, must guide process thinking, in order to provide conditions to an expected emerging feature the interaction between environment and system. It is justified to place the sustainable development concept at a strategic level in order that this will give the proper treatment for its transmission, internally, influencing the functioning of the parties to serve it, and, externally, by comparing the results of its processes through the context provided by the environment in which it takes part.

Operational level is characterized by performing tasks, providing the necessary conditions for achieving the goals set at the strategic level. Its focus is directed to occurring processes in the system (emphasis is placed on process thinking). ISO 9001:2008 [17], ISO 14001:2004 [18] and OHSAS 18001:2007 [19] have an operational level orientation. They do not actually set the tasks to be performed by the organization, because it is understood these are subject to organizational strategic objectives and these vary from organization to organization. Instead, they provide management guidelines that, in turn, may lead to the processes creation, from which a set of guiding practices in supporting the implementation of the tasks of the organization can be provided. Basically, the intent is to standardize work and optimize the resources use involved in the organization's production and services.

Tactical level is the mediator between strategic and operational level. It must be aware of what happens, both outside and inside the system, seeking constantly reconciling the tasks entrusted to the parties that make up the system with environment's demands.

All operations carried out by the organization result in impacts (positive, negative or neutral). Monitoring and evaluating the impacts, as well as their associated risks, is a key for maintenance resources purpose. ISO 31000:2009 [10] is the standard that establishes management guidelines in order to provide processes for monitoring and evaluating the impacts of operations carried out by organizations. Although it gazes directed at the operational level, it provides grants to implement the activities relegated to the tactical level. So it is positioned at this level.

Another aspect that lies at the tactical level is performing the necessary linkage to the organizational goals achievement. This implies not only relating to internally but also externally to meet those needs underlying the system, established at a strategic level. This is possible through ISO 26000:2010 [9] assistance.

Fig. 5 shows generic structure proposed for possible convergence among ISO standards for sustainable development internal system configuration, based on what was discussed about the relationship among organizational levels.

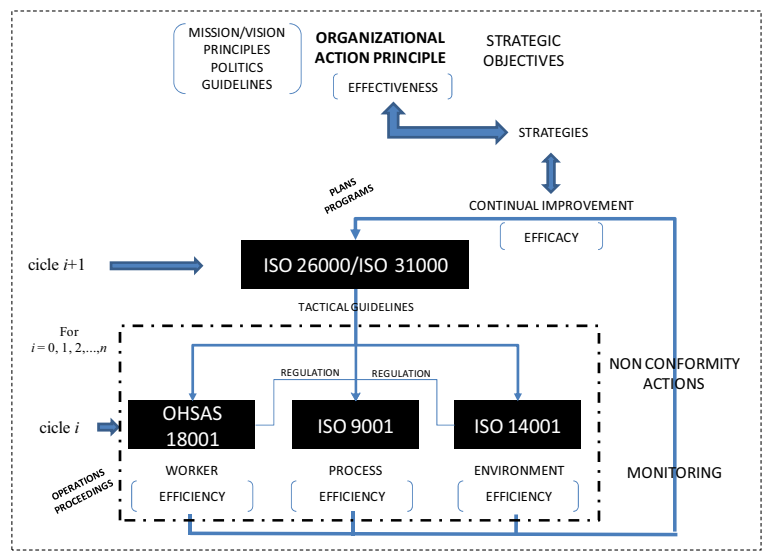

Fig. 5 - Generic structure for possible convergence internal system configuration. Source: Merlin [16].

The developed generic structure for possible convergence aims at the organization's inner functioning. Thus, the idealized functioning proposed by the generic structure for possible convergence in Fig. 5 should be examined through the Nadler and Tushman congruence model in regard to a possible convergence in organization's behavior to sustainable development induction.

In Nadler and Tushman model, strategy is the most important input, involving in its constitution the other inputs covered by the model. A known way for organizations to come up with its strategies is the organizational strategic planning. The strategy, as determined by the organization, is designed from the analysis of external and internal environment as well as from the personal intentions of its participants. The strategy is the result of contextual thinking. It rises from contextual analysis. Organization's strategies must be built, taking into account some issues related to sustainability (see [16] for details) in the strategic planning development.

It is assumed here that the idea of a sustainable development concept top down approach to provide favorable conditions for an attempt to induce sustainable development at the organization. That is, there must be commitment from the organization's strategic level, which should treat sustainability as 
organization's continuous strategic alignment to meet society's demands. However, it is understood that although there might be efforts by the organization, this does not guarantee that it can truly lead to its development in a sustainable manner.

While strategic planning, with emphasis on contextual thinking, provides the means for early indications in creating the conditions for the organization's sustainable development induction, management is the means of dissemination of the induction. It focuses on the system's objectives working both outside, aware of the demands of the environment, and within the system, aware of the internal demands and tasks to be undertaken by its component parts.

Fig. 6 shows the orientation between the management and ISO standards. In a top down approach, management is aided by ISO 26000:2010 [9] and ISO 31000:2009 [10], explaining their relationship with the environment, and a bottom-up approach (from operational results information flow), aided by ISO 9001:2008 [17], ISO 14001:2004 [18] and OHSAS 18001:2007 [19], explaining its relationship with system's parts.
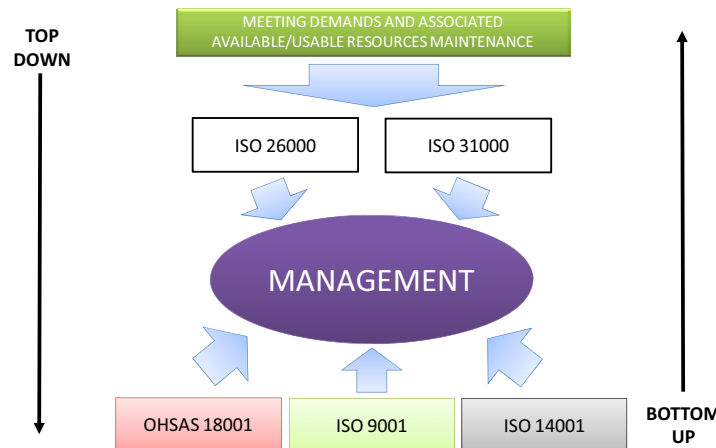

Fig. 6 - Management as an inductive element for organizational behavior and organizational objectives dissemination. Source: Merlin [16].

Another important aspect is represented by the development of organizational competencies. The organizational competence implies the "ability to act in accordance with the strategies, policies and objectives of the organization" (p.10) [15]. The idea of training to develop the organizational competencies is not restricted to the individual qualifications focused on the task, but on the pursuit of organizational efficacy. Understanding the expected results ran through the task [15].

Once organization has its conceptual issues strategically aligned with sustainable development concept and seeks achieving its strategic planning aware of this alignment, as well as management and competencies development, it is possible that it is in a way to sustainable development induction. Thus, the demands identified through the analysis of external and internal environment and defined organizational goals, strategies will be established to be disseminated and put into practice by the organization. If it is organization's interest to behave in a sustainable way, this behavior should occur both inside and outside its borders. Sustainable behavior is supposed to be a feature that emerges from its relations with society $[8,20]$

To induct a social responsible behavior, the organization needs to plan the necessary actions to the emergence of such feature. Before planning these actions, such behavior must be conceived strategically (treated at its conceptual issues [15]).

The planning phase consists of addressed issues by Clause 5 of ISO 26000:2010 [9], in which organization must recognize its social responsibility (respecting the principles of social responsibility, as specified in Clause 4), identification of the actors involved (stakeholders) that affect or are affected by the established strategies, and identifying the nature and needs of these issues (which can be used the key aspects contained in Clause 6 of the standard as a guide). With this information, the organization may establish its goals, the type of relationship that should establish with each actor involved to achieve the strategic organizational objectives. Defined relationship objectives, it shall establish the relationship strategies which will lead to a set of strategic actions for each of the actors involved, culminating in the preparation of plans and programs for possible relationships. Fig. 7 illustrates the planning phase for the system.

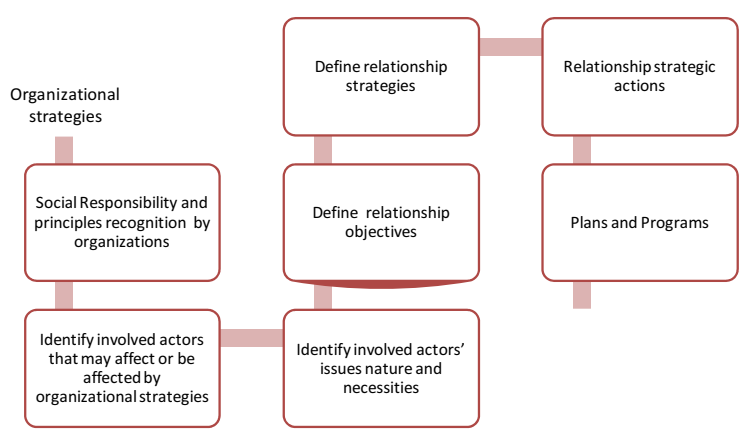

Fig. 7 - Planning step to induction of a possible organizational responsible behavior. Source: Merlin [16].

After the implementation and results verification stages, it follows to critical analysis to evaluate plans 
and programs in order to check whether the relationships established can be considered beneficial for both the organization (with respect to achieving its strategic goals) and the actors involved.

\subsection{ISO Standards management tools' parameters convergence analysis}

By analyzing ISO 26000:2010 [9], under the Nadler and Tushman model's lens, it has potential to induce a socially responsible organizational behavior, contributing to a possible system-environment and system-parts congruence. However, it is not guaranteed that this congruence will occur. Using this standard as a possible guideline may assist in articulating the organization's strategies, seeking to induce a possible organization's responsible behavior with the relationships established with all its stakeholders.

ISO 9001:2008 (p.V) [17] states that "it is not intended [...] impose uniformity in the structure of quality management system or uniformity of documentation". ISO 14001:2004 [18] and OHSAS 18001:2007 [19] are not explicit about this issue. They all suggest, in general, the establishment, implementation and maintenance of various procedures to coordinate and control activities. This systematic induces the emergence of patterns in the organization. This perception may be justified based on the facts presented, i.e. in ISO 9001:2008 Clause 8.5 [17], OHSAS 18001:2007 Clause 4.5.3.2 [19] and ISO 14001:2004 Clause 4.5.3 [18].

It is understood that standards are important since they allow the establishment of controls for purposes of progress and development of monitoring activities and their results over a given period [21]. However, the inertia caused by the same standard in the pursuit of consistent results might be an obstacle to necessary changes to the organization in order to adapt to changes imposed by the environment's demands (internal and external) [22]. A standard focuses more directly to the constancy of the organization, at a given level. However, a change characterizes breaks in consistency, requiring the organization's development and hence evolves to a new level in order to continue to meet the environment's demands [21].

As a result of standardization induction, the organization tends to stiffen the formal organization, in terms of processes and procedures, and the establishment of hierarchies, with a view to maximize organizational efficiency. This may reflect difficulties in the organization that operates in dynamic environments, in which the redefinition of strategies, and hence the reconfiguration of organizational elements is imperative to remain competitive in the market, i.e. the case of organizations operating in electronic and software development sectors.

Another important point to be exposed regards to the continuous improvement issue. Although these standards emphasize continuous improvement, it focuses in processes correction and prevention of non-compliances. This is evident in ISO 9001:2008 Clause 8.5 [17], OHSAS 18001:2007 Clause 4.5.3.2 [19] and ISO 14001:2004 Clause 4.5.3 [18].

There are evidences that ISO 9001:2008 [17], ISO 14001:2004 [18] and OHSAS 18001:2007 [19] do not have a proactive approach. This could be attributed to standardization issue, which ends up being induced in the organization for purposes of coordination and control. Proactive acting imply in a contingency posture, requiring greater flexibility and freedom of action in the organization. Oskarssom and Malmborg [22] explain that, when the organization chooses to work proactively in order to anticipate demands not sticking to the rules, they are able to experience greater freedom to act. Thus, it is possible that the proactive performance may be neglected by the standards because it tends to cause disruptions in an alleged pattern that they end up inducing or just being established in the organization. This may involve the creation of differences between individual and formal organization elements, treated in the Nadler and Tushman model.

With respect to the elements represented by the individual and informal organization (in Nadler Tushman model), the perception is that the standards tend to make these elements come on track to suit the task and the formal organization. This perception stems from the facts in ISO 9001:2008 Clause 6.2.2 [17], OHSAS 18001:2007 Clause 4.4.2 [19] and ISO 14001:2004 Clause 4.4.2 [18]. Although these standards explicit the need to train individuals in the organization, this training is expressed in terms of individual qualification to learn perform the task in the best and appropriated possible way towards the formal organization. It can be seen, then, that these three ISO standards provide a partial contribution to the development of organizational competencies. The contribution is called partial because they restrict the focus on individuals' technical skills. In search of conditions, to organization's sustainable development induction, individuals must have the awareness and the understanding on the conceptual issues of organization and also seek alignment to these issues. 
Analyzing the ISO 31000:2009 [10], viewed from the lens of Nadler and Tushman model, it works as an agent that will allow monitoring impacts caused by the tasks performed by individuals in the organization. The impacts are monitored based on the external environment and internal organization and therefore the identification of the actors involved. This can be evidenced in Clause 4.3.1 [10].It is important to state that, as ISO 31000:2009 [10] has focus on reducing the organization's identified risks, especially for those who may incur negative impacts. This may enable an induction of an appropriate combination among the Nadler and Tushman model four elements in search of mitigating organization's operations negative impacts. Another important issue is related to the process that the ISO 31000:2009 [10] suggests dealing with risk analysis. This process could lead to standardization of some activities performed in the organization and may have implications similar to those already discussed about the others ISO standards characterized at the operational level.

\section{Final Considerations}

From the discussions and analysis in this study, it is stated that ISO standards may contribute to sustainable development induction, if there is an alignment among their parameters, the strategic level and the organizations' internal and external environment demands. Although it is considered as a minimum recommendable condition, it cannot be said that under such circumstances sustainable development induction in the organization shall occur.

Organizational processes standardization implies the adoption of a systematic that may hinder the organization adaptability considering the environment in which it operates, in terms of agility and flexibility to meet its demands in a timely manner. In order to pursue a possible environment variability reduction, ISO standards needs being expanded to the entire chain which organization takes part. This may pose a major challenge for organizations who want a sustainable status. Since such feature emerges from its behavior and involves all those who participate in its operations (upstream and downstream), it will be necessary that all participants be engaged in seeking a sustainabilityoriented behavior.

\section{References}

[1] Estes, R. J. Toward sustainable development: from theory to praxis. Social Development Issues. v. 15, n. 3, p. 1-29, 1993.

[2] Pezzey, J. Sustainable Development Concepts. Washington, DC: The World Bank, 1992.

[3] UNWCED. Our Common Future (The Brundtland Report) Oxford, Oxford University Press, 1987

[4] Bertalanffy, L. Von. General Systems Theory: foundations, developments, applications. 1969.

[5] Capra, F. A teia da vida. São Paulo: Editora Cultrix, 1997.

[6] Jackson, M. C. Systems approaches to management. New York: Kluwer Academic, 2000, 448p

[7] Nadler, D. A.; Tushman, D. L. A model for diagnosing organizational Behavior: Applying a congruence perspective. Organizational Dynamics. 1980.

[8] Jorgensen, T. H.; Remmen, A.; Mellado, M. D. Integrated management systems - three different levels of integration. Journal of Cleaner Production. v. 14, p. 713-722, 2006.

[9] ISO 26000:2010. Guidance on social responsibility. International Standardization for Organization. Switzerland, 2010.

[10]ISO 31000:2009. Risk Management - Principles and Guidelines. International Standardization for Organization. Switzerland, 2009.

[11]Pacheco Júnior, W.; Pereira, V. L. D. V.; Pereira Filho, H. V. Pesquisa científica sem tropeços: abordagem sistêmica. São Paulo: Atlas, 2007

[12] Thiry-Cherques, H. R. O primeiro estruturalismo: método de pesquisa para as ciências da gestão. Revista de administração contemporânea. v. 10, n. 2, p. 137-156, 2006

[13]Richardson, J.R. et al. Pesquisa Social: métodos e técnicas. 3. ed. São Paulo: Atlas, 2008.

[14]Elkington, J. Enter the triple bottom line, in: Henriques, A.; Richardson, J. ed The triple bottom line: does it all add up? London: Earthscan Publications Ltd, cap. 1, p.1-16, 2004.

[15]Pacheco Júnior, W.; Pereira, V. L. D. V.; Pereira Filho, H. V. Gestão da segurança e higiene do trabalho: contexto estratégico, análise ambiental e avaliação das estratégias. São Paulo: Atlas, 2000

[16] Merlin, F. K. M.Sc. Análise de convergência dos parâmetros estabelecidos por meio das ferramentas de gestão do padrão ISO à indução do desenvolvimento sustentável nas organizações. Dissertação. Universidade Federal de Santa Catarina, 2011.

[17]ISO 9001:2008. Quality Management Systems - Requirements. International Standardization for Organization. Switzerland. 2008.

[18]ISO 14001:2004. Environmental Management Systems Requirements. International Standardization for Organization. Switzerland, 2004.

[19] OHSAS 18001:2007. Occupational Health and Safety Management Systems - Requirements. British Standard Institute. London, 2007

[20]Zwetsloot, G. I. J. M. From Management Systems to Corporate Social Responsability. Journal of Business Ethics. v. 44, n. 2-3, p. 201-207, 2003.

[21] Brunsson, N.; Jacobsson, B. A World of Standards. New York: Oxford Univ. Press, 2000.

[22] Oskarsson, F.; Malmborg, F. Von. Integrated management systems as a corporate response to sustainable development. Corporate Social Responsibility and Environmental Management, v.12, p.120-128, 2005. 